\title{
Design and Implementation of Terminal Logistics Distribution System Based on IOS Platform
}

\author{
Yufeng Zhuang ${ }^{1}$ and Rong Huang ${ }^{1, a}$ \\ ${ }^{1}$ Logistics Department of Automation School, Beijing University of Posts and Telecommunications, Beijing, China
}

\begin{abstract}
The logistics companies often face inefficient distribution and a multitude of customer complaints on the shopping festival. This paper will find out the existing terminal logistics distribution problems, and put forward some suggestions for improvement according to these problems. Combined with the suggestions, an application for the optimization of terminal logistics distribution based on IOS is designed and developed. The application can mainly be divided into order module, map navigation module and communication module. Couriers login the application, process the orders by using bar code technology and get the best solution of delivery by the map. It can improve the distribution efficiency and customer satisfaction to some extent.
\end{abstract}

\section{Introduction}

In 1998, China's first online transaction was completed, which marks the beginning of a new era of e-commerce in China. By 2012, the amount of online transactions in China is more than 10 trillion RMB [1]. As the online shopping is becoming more and more popular, the express industry has also developed rapidly. According to the statistics, in 2014, the amount of the national parcels was 13.96 billion, with a growth rate of $51.9 \%$ [2]. This shows that the express industry is growing rapidly and it plays an increasing important role in our daily life.

However, the express industry has also exposed a lot of problems, especially the "last mile" problem. According to the statistics of the State Post Bureau, 40930 consumer complaints were received in February 2012, of which 39783 were related to express delivery, accounting for $97.2 \%$ [3] of the total amount of complaints. Data show that express delays and delivery services are the two main complaints, accounting for $40.2 \%, 33 \%$ respectively. Thus, the problem of express delay is the most prominent. While in the express delivery process, the time of terminal logistics distribution accounts for a considerable proportion of the whole time of express delivery, so it is particularly important to improve the efficiency of terminal logistics distribution.

With the development of mobile Internet, smart phones have become popular. Google issued a report on the use of smart phones and the survey showed that China's smartphone penetration rate reached $44 \%$ in 2015 . The express industry should also follow the trend of the times and provide users with more efficient, more convenient, more flexible terminal delivery services by using intelligent mobile terminals.
Based on the background analysis above, this paper focuses on the problems in the distribution of the terminal logistics. And then constructive suggestions will be made to reduce the time or distance of delivery in order to improve the distribution efficiency, reduce logistics costs, and improve the customer satisfaction. At last, an application will be established, which can provide express queries as well as route planning.

\section{The system design}

As the figure 1 shows, the system is divided into two parts: IOS mobile terminal and the server. Logistics distribution station administrators and couriers use different devices to access the LeanCloud background cloud server through the network, and carry out the operation of the relevant database. Logistics distribution station administrators login the background system, and then they can view the message, communicate with the couriers, and deal with the emergency situations. The courier can login IOS mobile terminal by using the username and password. He can scan the express lists, and display the locations of the orders on the map, and then the system will plan the best path to help the courier improve delivery efficiency.

\section{The mobile terminal design}

This chapter mainly includes the analysis and solutions of the "last mile" problem, functional requirements analysis and business process design, and database design.

\footnotetext{
${ }^{a}$ Corresponding author: rongerhuang@ $126 . c o m$
} 


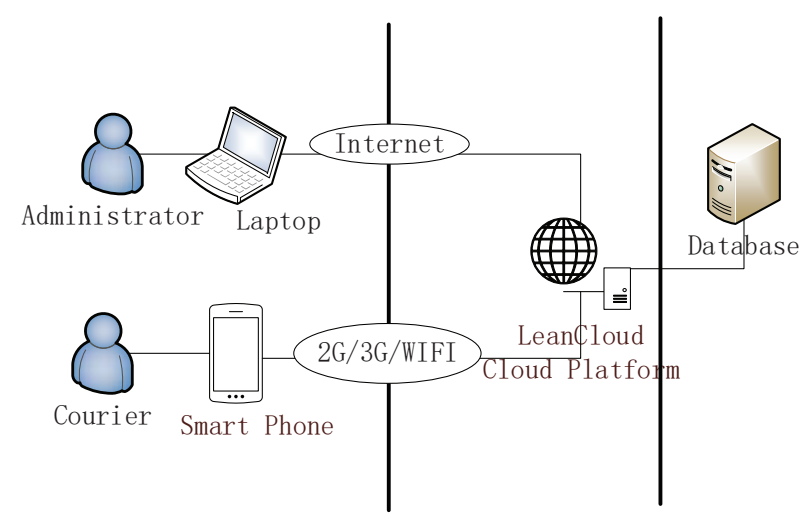

Figure 1. The system design

\subsection{The "last mile" problem and the solutions}

Through the analysis, there are three main problems in terminal logistics distribution:

- The service of logistics delivery is bad.

- Logistics delivery efficiency is low.

- The communication in the logistics delivery is impeded.

According the problems, evaluation and feedback system can be established to improve the service of couriers. It shows that good logistics delivery services can greatly improve customer satisfaction [4]. Meanwhile, electronic maps are applied for route planning. Data show that advanced information technologies, such as GIS technology and GPS technology, can improve the efficiency of logistics delivery and save costs [5]. What's more, more functions are added for better communication between couriers and customers.

\subsection{Functional requirements analysis and business process design}

According the analysis above, we can design the main functions of the application, which is shown in figure 2 :

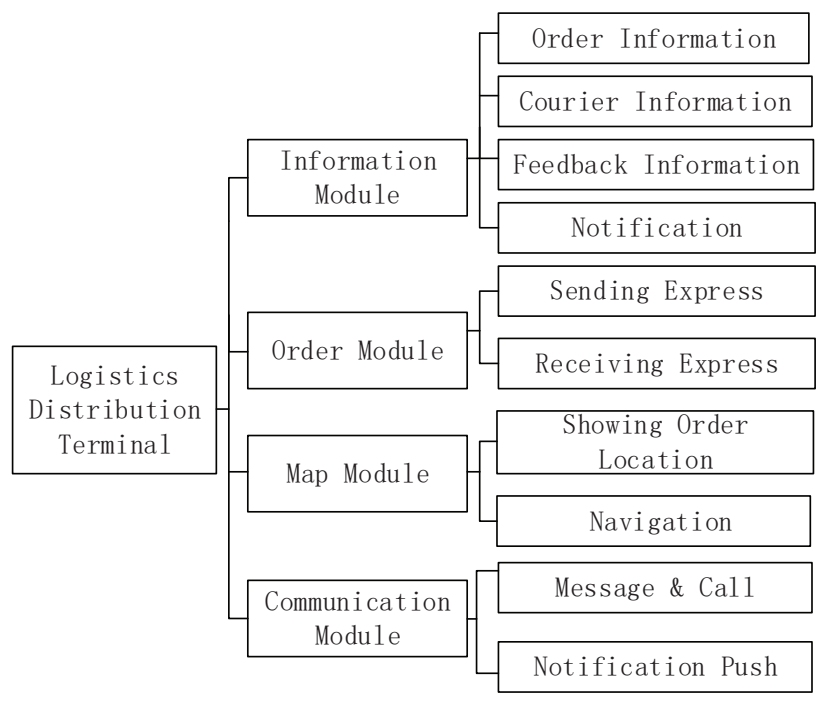

Figure 2. System functional module diagram
The application is mainly divided into four modules, the order module, the map module, the communication module and the basic information module. The order module has two functions which are receiving the express and delivering the express. The courier can use the application to scan the express lists to get the details of the orders and then the information will be added to the application. At the same time when the courier receives the express, new information of the order will be added into the database by scanning the bar code and filling in the express list. The map module can display all orders' addresses, plan the best path and navigate. The communication module can enable the couriers to communicate quickly with the distribution station and other couriers, and receive the push from the distribution station. The basic information module can maintain information, including the order information, the courier information, the evaluation information, pushes and so on.

This application mainly relates to the delivering phase and receiving phase in the general logistics delivery process. This application will refine the business process of the delivering phase and the receiving phase, and effectively improve the efficiency of the terminal logistics distribution. The figure 3 shows the delivering phase in the logistics delivery process.

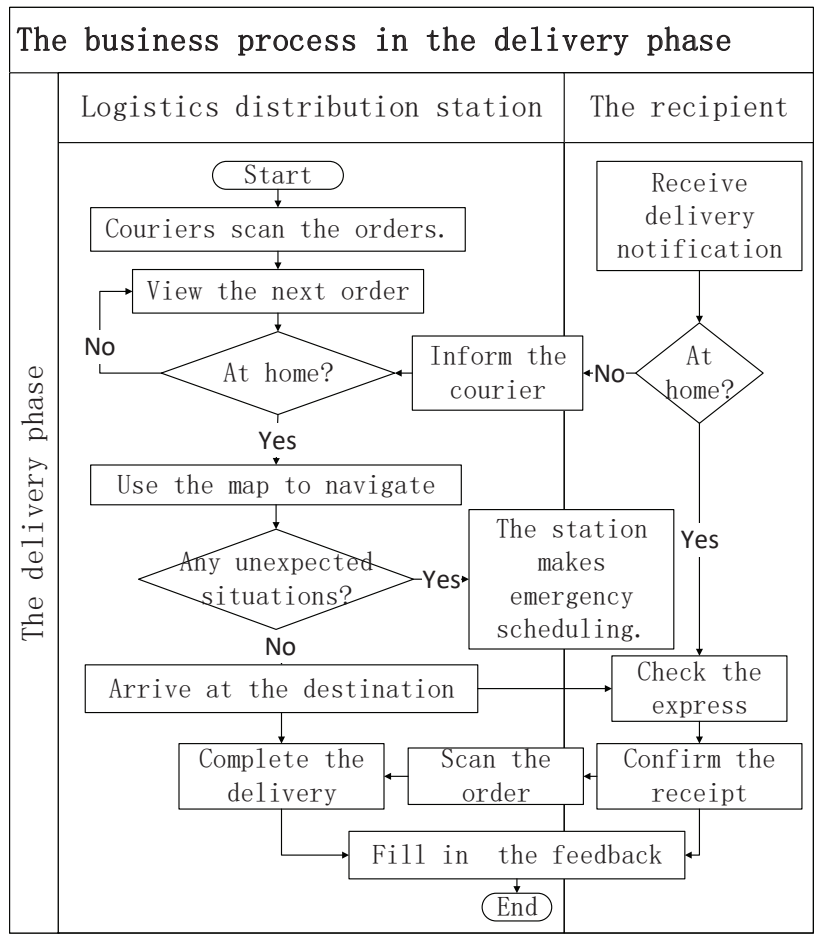

Figure 3. The delivering flowchart

\subsection{Database design}

This application uses a third-party server called LeanCloud for data storage. The database mainly consists of four tables, which are the order table, the courier table, the evaluation table and the push table. The order table includes the order number, the recipient's phone number and address, the sender's phone number and address, the status of the order and the attributes of the express, such 
as weight, payment method, and so on. The courier table includes the courier number, the username, password and mobile phone number. The evaluation table includes the order number, the courier number, and the scores. The push table includes the push number and the push content. The relational data model is shown as the figure 4:

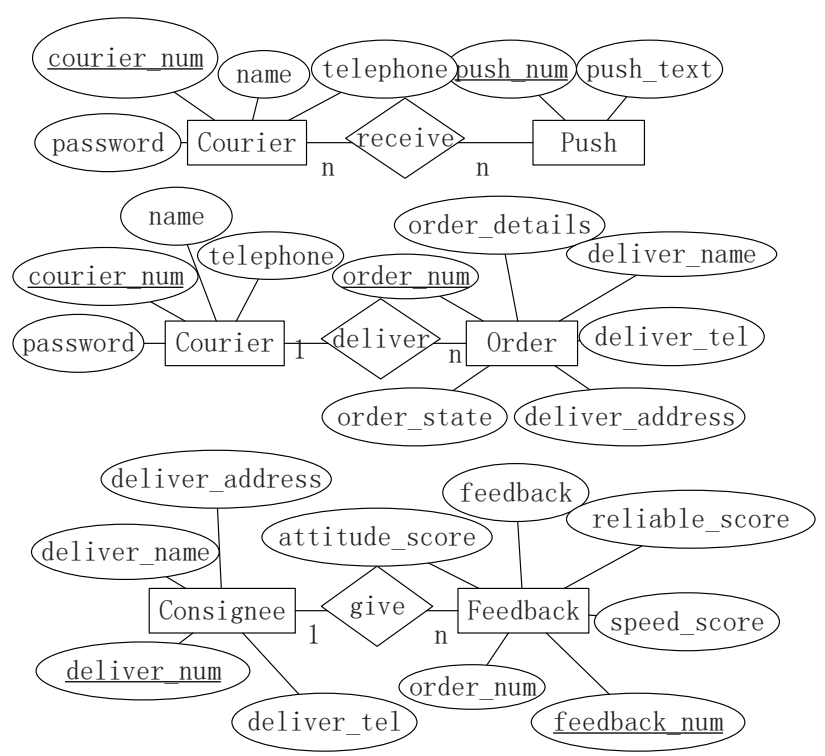

Figure 4. The ER diagram

\section{The implementation of the mobile terminal}

\subsection{The order module}

The order module can display the specific information of the order by scanning the bar code of the express list. When the courier completes the delivery, he needs to scan the express list to update the order state. After that the courier needs to invite the consignee evaluate the courier's services. The evaluation and feedback will be kept in the database, which standardize the courier's behaviours for better services to the public.

In the barcode scanning part, I use the third-party open source software called Zbar. Click on the 'Add' button, the system will automatically focus on the bar code by using camera, and the bar code number will appear in the text box below. According to the bar code, the system will connect to the database to query the order. The order details will be displayed on the mobile phone.

Figure 5 and figure 6 following show the effect.

\subsection{The map module}

In the map module, the electronic map can show the courier's current position and the locations of all orders. The specific address information will be shown on the label above the pin when the courier clicks on one of the pins on the map. When the courier clicks on the label, the application will automatically jump to the AMAP. The courier need not input the starting point and the end point. The system will default to the current position as a starting point, and the address on the label as the end point. The map will provide multiple driving routes. After the courier chooses one of them, the map will begin to navigate. Figure 7 and figure 8 show the effect of the map module:
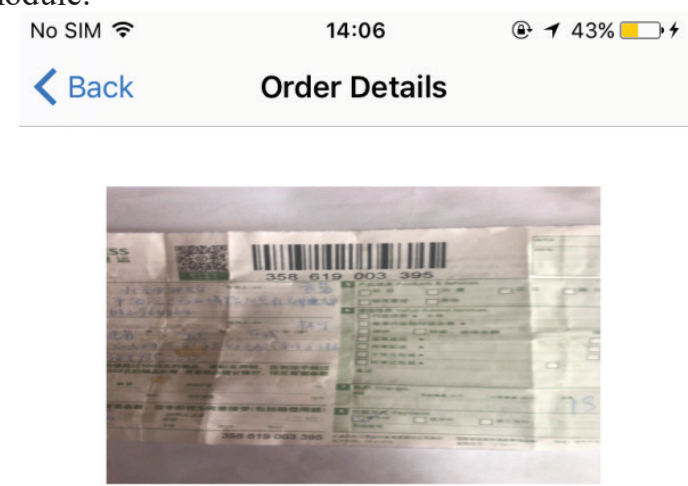

Order Num: 358619003395

Recipient: Devin

Telephone: 13478235678

Address: $\quad$ No 37, Xueyuan

Road, Haidian

District,Beijing

Add to tasks

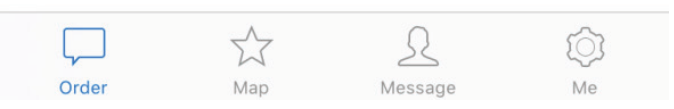

Figure 5. The effect picture of the barcode scanning part 


\begin{tabular}{|c|c|c|c|}
\hline No SIM ₹ & \multicolumn{2}{|c|}{$\begin{array}{c}14: 08 \\
\text { Order List }\end{array}$} & $\begin{array}{l}D^{4} \\
+\end{array}$ \\
\hline & Devin & 13478235678 & $>$ \\
\hline & Lisa & 15678345629 & $>$ \\
\hline & Rebecca & 13578648923 & $>$ \\
\hline & Molly & 15652915493 & $>$ \\
\hline & Linda & 15789645632 & $>$ \\
\hline & Rose & 15678964534 & $>$ \\
\hline & Tom & 15860124175 & $>$ \\
\hline & Ford & 18465208618 & $>$ \\
\hline & Wade & 13905481376 & $>$ \\
\hline & Jerry & 13749012678 & $>$ \\
\hline & Abel & 13789671045 & $>$ \\
\hline & Victor & 18905783450 & $>$ \\
\hline & limmv & $1365 \Delta 901 \Delta 67$ & $>$ \\
\hline & & $\Omega \quad\{\Omega\}$ & \\
\hline der & M & essage & \\
\hline
\end{tabular}

Figure 6. The effect picture of the order module

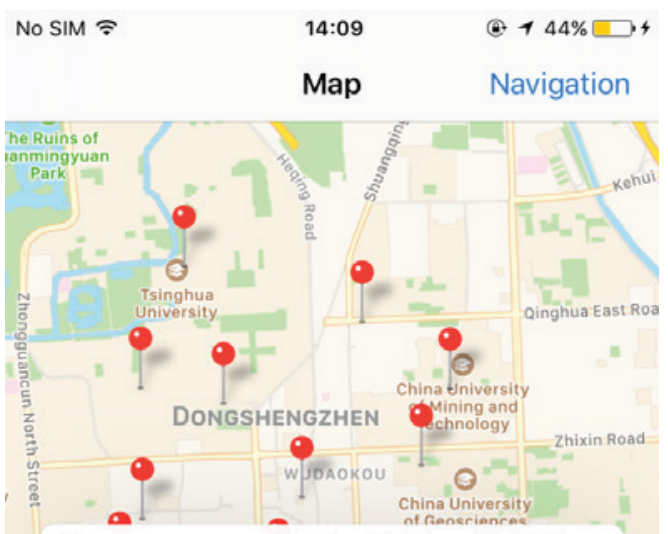

Zhongguancun Baofusi Bridge No.81 (... Rose 15678964534

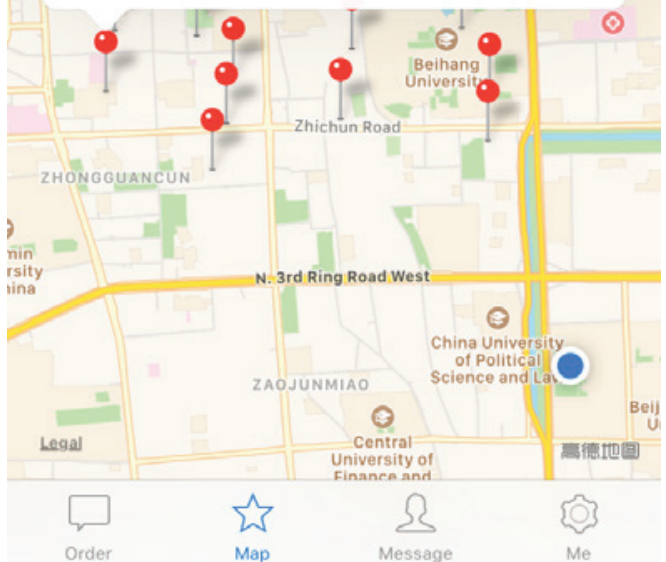

Figure 7. The first effect picture of the map module

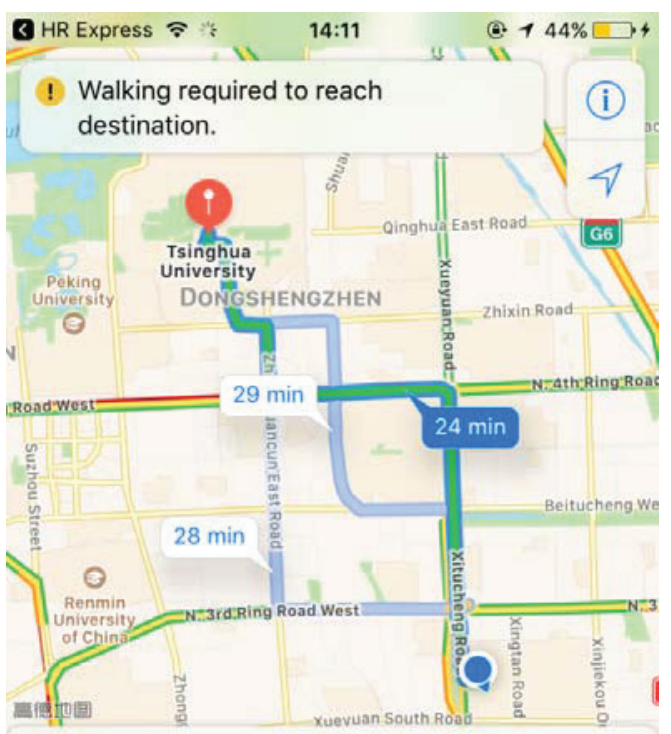

\section{To Tsinghua University}

From My Location

\section{$24 \mathrm{~min}$}

$7.1 \mathrm{~km} \cdot$ Xitucheng Road

Fastest route

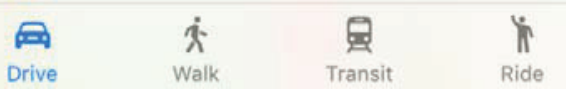

Figure 8. The second effect picture of the map module

\subsection{The communication module}

The communication module is used in two cases, one is that the courier can view the message from the logistics distribution station through the mobile terminal, and the courier can make a choice according to the message. For example, some recipients cannot accept the express temporarily. The courier can deliver the express next time when he sees the notification.

Another is that the courier can use the functions of telephone and SMS to save time when the courier encounters unexpected situations.

Figure 9 and figure 10 show the effect of the module.

\subsection{The basic information module}

The basic information module is mainly about the maintenance of some basic information including historical orders, feedbacks, pushes, courier information and so on.

Couriers can see and modify their basic information in this module, including username and password. At the same time, the courier can view the orders and the evaluations of the orders that he has already delivered.

The effect is as figure 11 shows. 


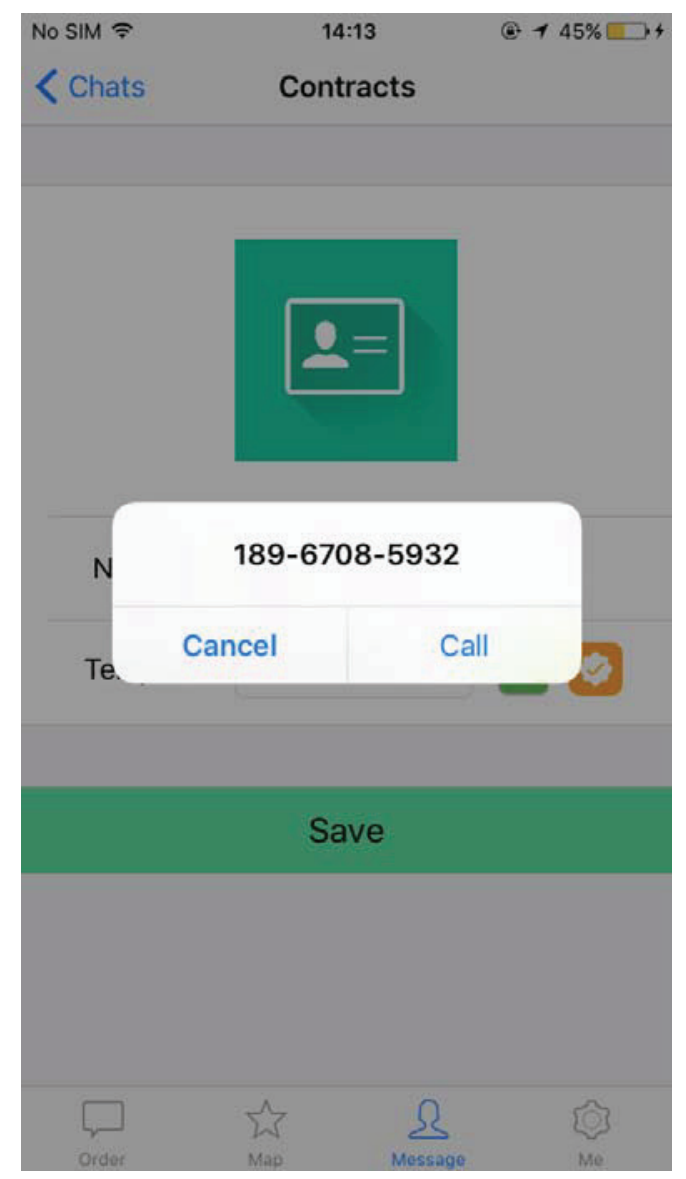

Figure 9. The effect picture of the communication module

$\begin{array}{lcc}\text { No SIM } ₹ & 14: 14 & \odot 146 \% \square \\ <M e & \text { Notification } & \end{array}$

Notification-1

Content: Please return to the distribution station before noon.

\section{Notification-2}

Content: The recipient of Order number PA568311380 is not at home.Please cancel the delivery.

\section{Notification-3}

Content: Please go to Beijing University of Posts and Telecommunications to pick up an express. The phone number is 15652957890 .

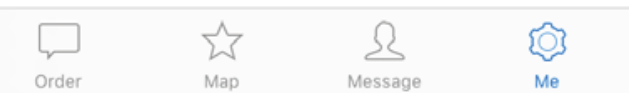

Figure 10. The effect picture of the notification part

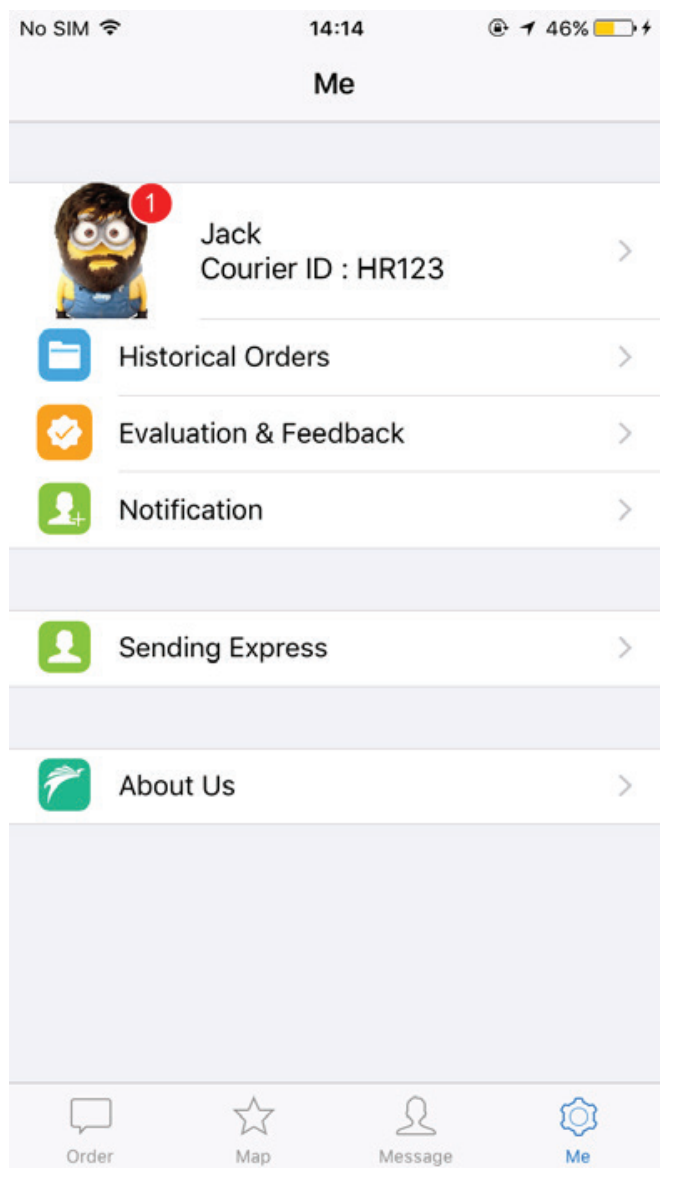

Figure 11. The effect picture of the basic information module

\section{Conclusion}

This paper mainly analyses the problems existing in the terminal logistics distribution, and puts forward some effective solutions according to these problems. According to these solutions, an application will be designed based on IOS platform which can provide express queries as well as route planning. The courier can effectively improve distribution efficiency and service quality by using the app.

After the test, the actual operation of this application is consistent with the expected effect. At the same time, the business logic is correct and the interaction is good. Facts have proved that it can be applied in practical work. Meanwhile, the design also needs to be improved in the daily work.

\section{Acknowledge}

I would like to thank my tutor, Professor Zhuang Yufeng. Mr. Zhuang made a lot of constructive suggestions to help me improve my paper. The teacher's rigorous work attitude and open mind have given me a lot of inspiration and encouragement, so that I can complete the paper successfully.

\section{References}


1. L. Kang, Research on Community Logistics Distribution System in Y Company Based on Electronic Business Platform (Nanchang University, 2014)

2. Z.Q. Yang, Research on the Multi-objective Vehicle Routing Optimization in Urban Express Distribution (Harbin Institute of Technology, 2015)

3. L.F. Xiao, Research on Commom Distribution Model for End of Logistics in B2C E-Commerce (Jinan University, 2013)

4. S. Holdorf, H.D. Haasis, G. Lacorata, 8th Int. Conf. on Software, Knowledge, Infromation Management and Applications (SKIMA), 1-6 (2014)

5. Y. Dai, B.S. Zhong, Logistics Technology, 11, 121123(2004) 